\title{
Laparoscopic Resection in Segment VIII: Diamond Technique
}

\author{
Víctor Molina $^{1} \cdot$ Manuel Rodríguez-Blanco ${ }^{1}$ Santiago Sánchez-Cabús ${ }^{1}$ \\ Received: 15 September 2021 / Accepted: 8 November 2021 / Published online: 8 January 2022 \\ (c) The Society for Surgery of the Alimentary Tract 2021
}

The laparoscopic resection of liver lesions located in the postero-superior segments can be challenging ${ }^{1}$. Hence, they are considered by the Iwate criteria as resections with an intermediate or advanced difficulty ${ }^{2}$. Cipriani et al. ${ }^{3}$ have described a technique for non-anatomical liver resection on postero-superior segments with good results and making this surgical resection easier.

We present the case of a 45-year-old woman with a metastatic breast cancer lesion in segment VIII. Resection following the Diamond technique principles was proposed.

Laparoscopic VIII subgmentectomy was performed with the diamond technique as Cipriani et al. described using an inverted L-shaped port placement. A resection from medial to lateral followed by inferior to superior margin was followed. Suprahepatic veins were exposed without injury with a total surgical time of $195 \mathrm{~min}$, pringle lasted $40 \mathrm{~min}$, and blood losses were $100 \mathrm{ml}$. Pathology showed a 2.1-cm-wide lesion with R0 margin. The patient was discharged on day 3 without complications.

Laparoscopic liver resection of postero-superior segments is feasible using the Diamond technique achieving R0 margins and avoiding suprahepatic vein injury.

Víctor Molina

vmolinahbp@gmail.com

1 HepatoBilioPancreatic Surgery Unit, Hospital de La Santa Creu I Sant Pau, Universitat Autònoma de Barcelona, C/ Sant Quintí, 89, 08041 Barcelona, Spain
Supplementary Information The online version contains supplementary material available at https://doi.org/10.1007/s11605-021-05210-y.

\section{Declarations}

Disclosures Drs. Víctor Molina, Manuel Rodríguez-Blanco, and Santiago Sánchez-Cabús have no conflict of interest or financial ties to disclose.

\section{References}

1. Abu Hilal M, Tschuor C, Kuemmerli C, López-Ben S, Lesurtel M, Rotellar F. Laparoscopic posterior segmental resections: How I do it: Tips and pitfalls. Int J Surg. 2020 Oct;82S:178-186.

2. Tanaka S, Kawaguchi, Y, Kubo, S, Kanazawa A, Takeda, Y, Hirokawa F, et al. Validation of index-based IWATE criteria as an improved difficulty scoring system for laparoscopic liver resection. Surgery. 2019; 165(4):731-740

3. Cipriani F, Shelat VG, Rawashdeh M, Francone E, Aldrighetti, L, Takhar A, et al. Laparoscopic Parenchymal-Sparing Resections for Nonperipheral Liver Lesions, the Diamond Technique: Technical Aspects, Clinical Outcomes, and Oncologic Efficiency. J Am Coll Surg. 2015;221:265-272

Publisher's Note Springer Nature remains neutral with regard to jurisdictional claims in published maps and institutional affiliations. 